\title{
Helicobacter cinaedi infection in patients with diabetes: a case report
}

\author{
Ryoichi Ishibashi ${ }^{1,2}$, Susumu Nakamura ${ }^{3}$, Minoru Takemoto ${ }^{1,2^{*}}$, Chiaki Mukai ${ }^{3}$ and Koutaro Yokote ${ }^{1,2}$
}

\begin{abstract}
Background: Helicobacter cinaedi causes bacteremia without characteristic clinical symptoms and is firstly isolated from human immunodeficiency virus (HIV)-positive homosexual men.

Findings: Here we describe, for the first time case report, two female patients with diabetes who had $\mathrm{H}$. cinaedi bacteremia. Some cases of $\mathrm{H}$. cinaedi bacteremia may require long-term administration of multiple antibiotics prior to the resolution of infection.

Conclusions: Therefore, these cases indicate that it is important to consider $\mathrm{H}$. cinaedi in patients with diabetes presenting with bacteremia, especially in patients with poor glycemic control.
\end{abstract}

Keywords: Helicobacter cinaedi; Bacteremia; Diabetes

\section{Introduction}

Helicobacter cinaedi is a Gram-negative enterohepatic bacterium of the Helicobacteraceae family that was first identified in 1985 among immunocompromised European and American men with human immunodeficiency virus (HIV) infections (Totten et al. 1985). In Japan, the isolation of $H$. cinaedi from blood culture was first reported in 2003 (Murakami et al. 2003), and it has since been occasionally isolated from samples obtained from patients with bacteremia and sepsis. In this report, we describe our experience with two patients with diabetes who had $H$. cinaedi bacteremia; in addition, we include a literature review.

\section{Case reports}

Case 1: A 76-year-old female with a history of slowly progressive type 1 diabetes, treated for 30 years. She was being treated for rheumatoid arthritis (oral prednisolone, $5 \mathrm{mg} /$ day, and had poor glycemic control specified by a glycated hemoglobin (HbA1c) level of $7.8 \%$ while on a regimen of $50 \%$ insulin lispro protamine suspension and $50 \%$ insulin lispro injection (HUMALOG ${ }^{\circ}$ Mix50/50TM;

\footnotetext{
* Correspondence: minoru.takemoto@faculty.chiba-u.jp

${ }^{1}$ Department of Clinical Cell Biology and Medicine, Chiba University Graduate School of Medicine, Japan 1-8-1 Inohana, Chuo-ku, Chiba-shi, Chiba 260-8670, Japan

${ }^{2}$ Division of Diabetes, Metabolism and Endocrinology, Chiba University Hospital, Chiba, Japan

Full list of author information is available at the end of the article
}

Lilly USA, LLC, 2013) at $6 \mathrm{U}$ in the morning and $4 \mathrm{U}$ in the evening, as well as miglitol (10 mg/day) and mitiglinide $(450 \mathrm{mg} /$ day). She presented to the emergency unit of our hospital with a fever of $39^{\circ} \mathrm{C}$, headache, erythema on the trunk, and joint pain. On admission, her body temperature was $40.2^{\circ} \mathrm{C}$, pulse rate 134 beats $/ \mathrm{min}$, blood pressure 150/70 $\mathrm{mmHg}$, height $145 \mathrm{~cm}$, and body weight $38 \mathrm{~kg}$. Routine laboratory testing showed an elevated leukocyte count of $11.8 \times 10^{3}$ cells $/ \mu \mathrm{L}$ and a C-reactive protein level of $19.21 \mathrm{mg} / \mathrm{dL}$. Serological tests for syphilis and HIV were negative. As a result, we suspected a bacterial infection, especially because of the significant inflammation reaction in blood sampling; therefore, we decided to begin empiric cefepime therapy at $2 \mathrm{~g} /$ day. During hospitalization, our patient complained of a decreased appetite; thus, we commenced blood glucose monitoring on a sliding scale to maintain her preprandial blood glucose level at approximately $120 \mathrm{mg} / \mathrm{dL}$. On day 2 of admission, her fever declined and erythema improved. On day 4 , she was discharged after a change to oral cefotiam at $1800 \mathrm{mg} /$ day. On day 9 , she again developed high fever, poor appetite, and fatigue, and on day 10, she was readmitted to our hospital. On the same day, $H$. cinaedi was detected from a blood culture taken on the first day of admission; we accordingly started administering minocycline at $200 \mathrm{mg} /$ day. A blood culture taken on the second day of re-admission was positive for $H$. cinaedi, indicating persistent bacteremia. However, 
because her general condition was improving, oral minocycline (200 mg/day) was continued. On day 18 after the initial admission, the third blood culture was taken, then she was discharged a second time. Later, we confirmed that her third blood culture was negative in an outpatient clinic and prescribed completion of the antibiotic regimen.

Case 2: A 47-year-old female diagnosed with type 2 diabetes 2 years before, and treatment started immediately thereafter. However, after a year, she stopped taking medications on her own decision. She presented to emergency department of our hospital with a fever of $38^{\circ} \mathrm{C}$ and bilateral lower leg pain for three days. She was hospitalized with a diagnosis of lower right leg cellulitis, and we began cefazolin administration at 3 g/day. On admission, her diabetic control was poor (HbA1c, 11.5\%, postprandial blood glucose, $268 \mathrm{mg} / \mathrm{dL}$ ); in addition, her body temperature was $39.2^{\circ} \mathrm{C}$, pulse rate 106 beats/min, blood pressure 137/71 $\mathrm{mmHg}$, height $166 \mathrm{~cm}$, and body weight $61 \mathrm{~kg}$. Routine laboratory testing showed an elevated leukocyte count of $13.8 \times 10^{3}$ cells $/ \mu \mathrm{L}$ and a Creactive protein level of $4.49 \mathrm{mg} / \mathrm{dL}$. Serological tests for syphilis and HIV were negative. Soon after starting antibiotic treatment, her fever subsided. Five days later, redness and swelling disappeared; therefore, we changed treatment to cefdinir at $900 \mathrm{mg} /$ day. She was discharged on day 8 . The following day, we confirmed $H$. cinaedi from the blood culture taken on day 1 ; nevertheless, we decided to adopt a wait-and-see approach because no exacerbation of disease was observed since her initial admission.

\section{Discussion}

$H$. cinaedi is a rare infection primarily detected among HIV-positive patients in western countries. In Japan, most patients with $H$. cinaedi infection were HIV-negative, but immunocompromised (Araoka et al. 2014). H. cinaedi settles in the digestive tracts of humans, monkeys, dogs, and cats. Some cases of hospital-acquired outbreaks have also been reported (Rimbara et al. 2012). Neither of our patients had contact with animals, and because they came from different villages, they had no previous contact each other. Hence, the routes of infection remain unknown. Case 1 was prescribed $5 \mathrm{mg}$ of prednisolone per day for rheumatoid arthritis, and both patients had poorly controlled diabetes. It has been reported that migratory, antiinfection, and phagocytic functions of leukocytes are compromised in patients with diabetes especially by high glucose levels. Therefore, patients with poorly controlled diabetes might be at a higher risk for $H$. cinaedi infection. However, there is no consensus on characteristic clinical symptoms of $H$. cinaedi infection and $H$. cinaedi is a fastidious organism, thereby making it difficult to clinically diagnosis.
The average separation and processing period of a blood culture to detect $\mathrm{H}$. cinaedi is 5 days (Araoka et al. 2014), and the frequency of positive blood culture samples is reported to be $0.22 \%$ (Araoka et al. 2014). The actual frequency is probably higher because culturing this organism is difficult. Other reports have advocated genetic analyses, such as 16S-rRNA sequence and PCR-restriction fragment length polymorphism analyses (Oyama et al. 2012), for definitive diagnosis, although these methods are not feasible for routine laboratory analysis due to imbalance in cost-benefit ratio to detect very rare organisms. No guidelines have been provided for the treatment of $H$. cinaedi infections, even though this organism is reportedly sensitive to many antibiotics. In general, cephalosporins, carbapenems, tetracyclines, and aminoglycosides were found to be effective; however, various $H$. cinaedi isolates in Japan have shown increased resistance to penicillins and resistance to macrolides and quinolones (Kawamura et al. 2014). Therefore, some cases of $H$. cinaedi bacteremia may require long-term administration of multiple antibiotics prior to the resolution of infection.

In conclusion, two patients with poorly controlled diabetes presented with $H$. cinaedi bacteremia. Because $H$. cinaedi develops no characteristic clinical symptoms, it is important to consider $H$. cinaedi infection, especially in patients with poorly controlled diabetes who experience a relapse of infection after curative antibiotic treatment.

\section{Consent}

Informed consent was obtained from all patients for being included in the study and for publication of this Case report.

\section{Competing interests}

The authors declare that they have no competing interests.

\section{Authors' contributions}

$\mathrm{RI}$ researched data. SN researched data. MT wrote the manuscript and researched data. CM research data. KY contributed to the discussion and reviewed/edited the manuscript. All authors read and approved the final manuscript.

\section{Author details}

Department of Clinical Cell Biology and Medicine, Chiba University Graduate School of Medicine, Japan 1-8-1 Inohana, Chuo-ku, Chiba-shi, Chiba 260-8670, Japan. ²Division of Diabetes, Metabolism and Endocrinology, Chiba University Hospital, Chiba, Japan. ${ }^{3}$ Kimitsu Chuo Hospital, Chiba, Japan.

Received: 10 November 2014 Accepted: 29 January 2015

Published online: 10 February 2015

\section{References}

Araoka H, Baba M, Kimura M, Abe M, Inagawa H, Yoneyama A (2014) A

Clinical characteristics of bacteremia caused by Helicobacter cinaedi and time required for blood cultures to become positive. J Clin Microbiol 52:1519-1522 
Kawamura Y, Tomida J, Morita Y, Fujii S, Okamoto T, Akaike T (2014) Clinical and bacteriological characteristics of Helicobacter cinaedi infection. J Infect Chemother 20:517-526

Murakami H, Goto M, Ono E et al (2003) Isolation of Helicobacter cinaedi from blood of an immunocompromised patient in Japan. J Infect Chemother 9:344-347

Oyama K, Khan S, Okamoto T et al (2012) Identification of and screening for human Helicobacter cinaedi infections and carriers via nested PCR. J Clin Microbiol 50:3893-3900

Rimbara E, Mori S, Matsui M et al (2012) Molecular epidemiologic analysis and antimicrobial resistance of Helicobacter cinaedi isolated from seven hospitals in Japan. J Clin Microbiol 50:2553-2560

Totten PA, Fennell CL, Tenover FC et al (1985) Campylobacter cinaedi (sp. nov.) and Campylobacter fennelliae (sp. nov.): two new Campylobacter species associated with enteric disease in homosexual men. J Infect Dis 151:131-139

Submit your manuscript to a SpringerOpen ${ }^{\circ}$ journal and benefit from:

- Convenient online submission

- Rigorous peer review

- Immediate publication on acceptance

- Open access: articles freely available online

- High visibility within the field

- Retaining the copyright to your article

Submit your next manuscript at $>$ springeropen.com 